\title{
Menggali Eksistensi Rainsford dan Zaroff, Analisis Filosofis terhadap The Most Dangerous Game Karya Richard Connell
}

\author{
Edria Sandika \\ Prodi Bahasa dan Sastra Inggris, Fakultas Ilmu Budaya Universitas Andalas, Padang \\ E-mail: edriasandika@gmail.com
}

\begin{abstract}
This article discusses famous short story by Richard Connell entitled The Most Dangerous Game. It seek to explore the meaning of main characters' existence from philosophical perspective. The finding of this article is that both main characters (Zaoff and Rainsford) each represent the concept of bad faith and authentic in search of their existence. This short stories itself also represents the importance of existence/survival facing the reality of hunting and being hunted.
\end{abstract}

Keywords - existentialism, the most dangerous game, bad faith, authenticity, survival, philosophy.

\section{PENDAHULUAN}

The Most Dangerous Game merupakan cerita pendek karangan Richard Connell yang dirilis pada tahun 1924. Cerpen ini mengisahkan usaha bertahan hidup seorang Sanger Rainsford dari ancaman permainan yang direkayasa oleh Jendral Zaroff, seorang pelarian dari Rusia, yaitu permainan berburu antar manusia (man-hunting). Cerpen ini bermotif survival (bertahan hidup) ini sangat populer dan diadaptasi ke berbagai bentuk lainnya seperti film dan sandiwara radio. Motif cerita ini kelak nantinya populer dalam bentuk karya-karya lainnya seperti Battle Royale, The Maze Runner, ataupun The Hunger Games.

Secara ringkas, The Most Dangerous Game berkisah tentang seorang pemburu bernama Sanger Rainsford yang terdampar di sebuah pulau terpencil di lautan Karibia. Rainsford bertemu dengan dua orang pemukim pulau yang bernama "Ship-trap Island" yaitu Jenderal Zaroff dan pelayannya yang bernama Ivan. Keduanya merupakan pelarian dari Rusia sejak gejolak kaum Bolshevik yang terjadi di sana pada tahun $1917^{1}$. Mereka bertiga terlibat dalam permainan berburu dan diburu yang mana Rainsford memilih untuk menjadi yang diburu. Rainsford berhasil

\footnotetext{
'Lebih tengkap bisa disimak di Sparknote's Historical Context of The Most Dangerous Game, diakses November 2013
}

membunuh Ivan dan melakukan duel satu lawan satu dengan Zaroff. Meskipun tidak memiliki akhir yang jelas, narasi cerita mengindikasikan Rainsford memenangkan pertarungan dan menggantikan posisi Zaroff.

Motif cerita yang bertema permainan bertahan hidup (survival game) merupakan motif yang sering ditemukan dalam berbagai media, baik berupa fiksi naratif ataupun bentuk permainan interaktif yang mencerminkan sisi natural manusia, Istilah survival of the fittest dipakai oleh Herbert Spencer setelah memahami The Origin of Species karya Charles Darwin di dalam bukunya Principles of Biology $(1864)^{2}$, yang menguraikan bagaimana alam menentukan makhluk hidup apa yang bertahan dalam perjuangan hidupnya. Pemaknaan ini diartikan dan diinterpretasikan secara lebih luas dan cenderung disalahpahami.

Penulis melihat motif survival ini dalam kaitannya dengan pandangan filosofis eksistensialisme. Motif tersebut bisa diungkapkan melalui karakter Sanger Rainsford dan Jenderal Zaroff.

Thomas Flynn di dalam bukunya, Existentialism A Very Short Introduction (2006) mengungkapkan bahwa Eksistensialisme merupakan filsafat mengenai individu yang konkrit. Dalam kehidupan sosial masyarakat yang penuh dengan berbagai

\footnotetext{
${ }^{2}$ Surat Wallace kepada Darwin, bisa disimak di situs Darwin Correspondence Project, diakses 13 November 2013
} 
bentuk komunikasi dan kehancuran masif, individu yang eksis atau bertahan merupakan sebuah pencapaian yang tidak bersifat permanen. Semua manusia merupakan mahkluk hidup namun harus mampu menjadi manusia yang eksis dengan cara menerima segala konsekuensi dari tindakan yang telah dilakukannya ${ }^{3}$. Di dalam kehidupan sehari-harinya, manusia kebanyakan selalu lari dari kenyataan dan tidak mau mengakui apa yang telah dilakukannya. Semua itu dilakukan sematamata agar tidak dipersalahkan oleh orang lain.

Pemikir eksistensialis berfokus pada eksistensi manusia yang konkrit daripada esensi yang dimilikinya. Seseorang yang eksistensialis dianggap mampu membangkitkan kebenaran yang dimilikinya. Di dalam dunia ini, para eksistensialis mampu mengatur fenomena paling personal dalam dirinya, yaitu waktu dan ruang (space and time). Kedua hal tersebut berfungsi sebagai penentu dari sikap dan pilihan yang diambil ${ }^{4}$.

Ada dua konsep di dalam eksistensialisme yang penting untuk dicermati yaitu bad faith dan authenticity. Bad faith (kepercayaan yang buruk) merupakan bentuk manipulasi bagi diri sendiri yang intinya adalah menolak keutuhan seorang individu dan hanya menuruti apa yang terjadi ( $g o$ with the flow). Bad faith akan terjadi bila seseorang menolak segala tanggung jawab yang terjadi dalam situasi yang dimiliki seorang individu ${ }^{5}$. Sementara authenticity (otentisitas) merupakan salah satu fitur yang dimiliki oleh seorang eksistensialis, dimana seseorang tersebut mengakui keindividualitasannya. Seseorang tersebut percaya akan kenyataan yang ada di sekelilingnya. Menjadi seorang yang otentik berarti seseorang tersebut harus bersikap sebagai dirinya sendiri, bukan menjadi orang lain karena individu tersebut memiliki kebebasan penuh terhadap dirinya ${ }^{6}$.

Tulisan ini bertujuan untuk melihat aspek bad faith dan authenticity yang dimiliki oleh masingmasing karakter yang terlibat di dalam cerita The Most Dangerous Game. Hal ini didasari oleh posisi mereka dalam menunjukkan eksistensinya berusaha untuk bertahan hidup. Artikel ini juga mengungkapkan bagaimana pentingnya filosofi

\footnotetext{
${ }^{3}$ Lihat Flynn (2006) bagian Acknowledgement.

${ }^{4}$ Ibid, 8

${ }^{5}$ Ibid, 70

${ }^{6}$ Ibid, $74-80$
}

hidup eksistensialis dalam menghadapi tantangan hidup seperti yang dihadirkan oleh cerpen ini.

\section{ANALISIS FILOSOFIS EKSISTENSI KARAKTER DALAM THE MOST DANGEROUS GAME}

Membaca dan mendeskripsikan karakter General Zaroff yang manipulatif, penuh kepercayaan diri, dan kejam, pembaca bisa menemukan kontradiksi perilaku tersebut dengan latar belakangnya yang cenderung tidak memiliki pendirian. Jenderal Zaroff merupakan representasi bad faith yang jelas tergambarkan dalam cerita The Most Dangerous Game ini. Sebagai seseorang yang hobi berburu, dalam konteks cerita ini, berburu manusia, Zaroff justru memilih lari dari Rusia setelah gejolak yang terjadi di sana. Zaroff mengungkapkannya saat berbincang dengan Rainsford bahwa "After the debacle in Russia I left the country, for it was imprudent for an officer of the Czar to stay there" (5). Sebagai seorang pegawai yang mengabdi pada Tsar, Zaroff mencari pembenaran hobinya akan 'memburu' karena ketakutan dirinya yang 'diburu' akibat statusnya tersebut.

Ini merupakan bentuk penolakan terhadap identitasnya yang meskipun bisa dimaklumi sebagai usaha untuk menyelamatkan nyawanya dari ancaman kaum Bolshevik, tetapi tindakannya melarikan diri dari Rusia adalah bentuk penolakan tanggung jawab identitas dirinya karena Zaroff justru tetap melanjutkan hobinya dalam 'berburu manusia'. Ini menciptakan paradoks perilaku dan identitas yang pengecut, bermain aman, dan lari dari kenyataan. Hobi berburu menjadi bentuk penyangkalan akan ketakutannya ditangkap dan dibunuh oleh pemerintahan Rusia yang beralih dari Tsar menjadi Soviet.

Zaroff menginginkan hewan buruan favoritnya seperti yang digambarkannya pada Rainsford:

"I wanted the ideal animal to hunt," explained the general. "So I said, 'What are the attributes of an ideal quarry?' And the answer was, of course, 'It must have courage, cunning, and, above all, it must be able to reason." (7)

Keinginan Zaroff terhadap hewan buruan idealnya tersebut merupakan usaha untuk menutupi kelemahannya yang tidak memiliki 
keberanian (courage), kelihaian (cunning), dan beralasan (to reason) untuk bertahan di negeri asalnya. Memilih harus mengasingkan diri di pulau terpencil demi memuaskan hasratnya berburu hewan yang bernama manusia merupakan konsekuensi dari kelemahannya tersebut. Sebagai 'hewan' yang memiliki kemampuan untuk beralasan (must be able to reason), eksistensi seorang Zaroff dalam kehandalannya dalam berburu (hunter) terpaksa harus dibuktikan oleh kehadiran manusia lainnya. Tentu saja ini menjadi ironi tersendiri karena Zaroff secara tidak langsung telah meletakkan posisinya juga sebagai yang diburu (hunted). Sehingga permainan paling berbahaya yang dia ciptakan merupakan justifikasi atau pembenaran terhadap ketidakmampuan dirinya dalam menunjukkan eksistensi diri.

Sanger Rainsford, di lain pihak, merupakan kebalikan dari Jenderal Zaroff dalam usahanya bertahan hidup dan menunjukkan eksistensinya. Setelah menyadari situasi yang dialaminya, Rainsford tidak ragu dalam menentukan pilihannya, memilih untuk menjadi yang diburu (authenticity atau otentisitas). Dia memilih posisi moral yang jelas dalam menghadapi ide Zaroff dalam berburu manusia. Justifikasi Zaroff terhadap pengalaman perang yang dialami Rainsford bisa dipatahkan oleh Rainsford bukan sebagai pemburu melainkan menjadi pembunuh berdarah dingin.

"I can't believe you are serious, General Zaroff. This is a grisly joke."

"Why should I not be serious? I am speaking of hunting."

"Hunting? Great Guns, General Zaroff, what you speak of is murder."

The general laughed with entire good nature. He regarded Rainsford quizzically. "I refuse to believe that so modern and civilized a young man as you seem to be harbors romantic ideas about the value of human life. Surely your experiences in the war--"

"Did not make me condone cold-blooded murder, "finished Rainsford stiffly." (8)

Rainsford dengan tegas menentukan posisinya sebagai pemburu, bukan pembunuh. Meskipun terkesan moralis dan naif tetapi Rainsford justru menunjukkan apa yang sangat kontradiktif dimaknai oleh Zaroff seperti pada saat mereka beradu argumen

"I have electricity. We try to be civilized here."

"Civilized? And you shoot down men?" (9)

Rainsford bisa menunjukkan eksistensinya sebagai seorang pemburu yang menganggap berburu manusia itu tidaklah beradab (civilized). Dia tidak berusaha menjadi sama seperti Zaroff karena Rainsford tetap dalam pendiriannya sebagai dirinya sendiri. Dia bertanggung jawab terhadap apa yang disenanginya dalam berburu.

Meskipun pada akhirnya Rainsford terpaksa harus mengikuti permainan yang dibuat oleh Zaroff, dia tidak menyerah dalam situasi tersebut. Dia berusaha mengalahkan Zaroff dan membuktikan padanya bahwa Zaroff tidak bisa lagi tidur di kasur miliknya lagi. Terlepas dari tidak jelasnya akhir dari cerita, indikasi Rainsford memenangkan permainan ini bisa terlihat dari pernyataan terakhirnya "He had never slept in a better bed, Rainsford decided" dan membuktikan keberadaannya di hadapan Zaroff.

Rainsford adalah bentuk perlawanan ketiadaan eksistensi yang dimiliki oleh Zaroff. Rainsford dengan otentisitas yang dimilikinya percaya akan kenyataan yang ada di sekelilingnya dan menolak menyerah, tetapi berjuang untuk keberlangsungan hidupnya (dan tentunya eksistensinya sendiri). Rainsford tetap menjadi diri sendiri dan tidak terpengaruh pandangan Zaroff karena eksistensi seorang Rainsford bebas memilih untuk dirinya sendiri.

The Most Dangerous Game mengajarkan kepada pembaca arti penting eksistensi seorang individu dalam menghadapi tantangan dalam hidup, terutama saat hidup tersebut menjadi taruhan. Sanger Rainsford dan Jenderal Zaroff adalah dua representasi yang saling bertolak belakang atas pembenaran yang terjadi pada masing-masing karakter. Rainsford merupakan perwujudan akan kesadaran yang meskipun terkesan moralis, naif, dan mengandung pembenaran akan kegemarannya berburu (dalam konteks ini, membunuh makhluk hidup lainnya), tetapi diberi kesempatan untuk membuktikan eksistensi dirinya melalui permainan paling berbahaya yang dirancang Zaroff. Rainsford sanggup untuk bertahan hidup dan tidak menjadi alat pembenaran pemahaman Zaroff terhadap 
mangsa yang berkemampuan untuk beralasan, sehingga layak diburu.

Sebaliknya, Jenderal Zaroff adalah perwujudan ketiadaan eksistensi seorang pria yang 'lari dari kenyataan' sebagai seorang yang seharusnya diburu, tetapi mencari pembenaran untuk bisa menjadi seorang yang memburu. Identitas Zaroff sebagai seorang Cossack (orang Rusia) hilang dan menjadi contoh pemburu / pembunuh berdarah dingin melalui permainan berburu manusia tersebut. Zaroff harus memanfaatkan permainan paling berbahaya menurutnya itu agar diakui keberadaannya dan mampu menutupi ketidakberdayaannya kehilangan tanah air, identitas, dan naluri moralis akan penghargaan pada sesama manusia.

\section{KESIMPULAN}

Sebagai sebuah fenomena, eksistensialisme telah melewati masanya. Eksistensialisme telah meninggalkan jejak yang mempengaruhi diskursus kehidupan manusia. Namun sebagai gerakan filsafat, eksistensialisme terus berperan sebagai pembela dari kebebasan individu, keotentikan, ataupun tanggung jawab yang masih terus dibahas hingga saat ini.

Eksistensialisme adalah sebuah jawaban dari keresahan seorang individu dalam memaknai dirinya terhadap dunia. Dengan gerakan ini, manusia bisa tersadar dari apa yang membelenggu mereka selama ini. Manusia harus mampu mengenali diri mereka sendiri dan tahu harus bersikap menghadapi dunia dengan segala ambiguitas dan diskursus di dalamnya.

The Most Dangerous Game adalah cerita pendek yang memfokuskan formula naratifnya akan motif bertahan hidup. Cerita ini mempertanyakan eksistensi diri seorang Rainsford dan Zaroff dalam memaknai tantangan yang mereka hadapi masing-masing. Zaroff secara tidak langsung menyangkal realita yang dialaminya seperti dia menyangkal kelemahan diri sendiri yang kehilangan identitas. Sebaliknya, Rainsford yang meskipun tidak menyetujui permainan yang dilakukannya bersama Zaroff tersebut mampu memberikan argumen eksistensinya yang memang bertujuan untuk bertahan hidup.

Perilaku Zaroff tersebut merupakan representasi sikap bad faith yang memperbolehkan individu lain menentukan identitas yang membuat posisi dirinya menjadi nyaman, padahal realitanya tidak ada perbedaan apapun antara Zaroff dan Rainsford di dalam permainan ini. Kedua karakter adalah sama-sama pemburu sekaligus sama-sama mangsa yang diburu. Sikap percaya diri (self-confidence) seorang Zaroff adalah pembenaran dari sikap menipu diri sendiri (self-deception). Dia menjadi individu yang tidak bebas oleh identitas dan hobi berburunya sendiri.

Rainsford di lain pihak membuktikan posisi eksistensi dirinya sendiri dengan tetap sebagai seorang pemburu. Meskipun permainan yang dimainkannya bersama Zaroff penuh dengan adu argumentasi karena mangsa yang dimaksud adalah manusia, Rainsford tetap pada sikapnya yang memilih untuk diburu, di saat yang sama, juga memilih untuk memburu. Eksistensi Rainsford sebagai pemburu tetap terjaga dan mampu menerima kenyataan yang terjadi di sekelilingnya dalam waktu yang singkat. Hal ini terjadi karena situasi permainan berburu itu sendiri yang mempertaruhkan nyawa. Tentunya moralitas seorang Rainsford bisa dipertanyakan dan identitasnya dalam pilihannya ikut dalam permainan paling berbahaya itu membuatnya tak berbeda dengan Zaroff. Tetapi Rainsford mampu membuktikan bahwa dia bisa menjadi dirinya sendiri dan tidak berada dibawah bayang-bayang seorang pelarian dari Rusia yang mencari pembenaran akan hobinya tersebut.

Pada akhirnya cerita The Most Dangerous Game berhadapan pada dua posisi eksistensi seorang Rainsford dan Zaroff. Rainsford tidak memerlukan seorang manusia sebagai mangsa untuk menunjukkan eksistensinya sendiri sebagai seorang pemburu. Sementara Zaroff tidak mampu berdiri sendiri dalam identitasnya dan membutuhkan seorang Sanger Rainsford untuk menunjukkan eksistensinya sebagai pemburu.

\section{DAFTAR PUSTAKA}

[1] Abrams, M.H. A Glossary of Literary Terms: Ninth Edition. 2009. Boston: Wadsworth Cengage Learning.

[2] Connel, Richard. The Most Dangerous Game. Archieve.org. Internet Archieve. Web. Diakses 29 Nov 2013

[3] Copleston, Frederick. A History of Philosophy Volume IX: Modern Philosophy. 1994. New York: Doubleday Dell Publishing Group.

[4] Darwin Correspondence Database, http://www.darwinproject.ac.uk/entry-5140. Diakses 3 Jan 2014

[5] Flynn, Thomas. Existentialism A Very Short Introduction. 2006. New York: Oxford University Press

[6] Hart, Kevin. Postmoderrnism A Beginner's Guide. 2004. Oxford: Oneworl Publication. 
[7] Powell, Jim. Postmodernism for Beginners. 1998. New York: Writers \& Readers Publishing.
[8] SparkNotes Editors. SparkNote on The Most Dangerous Game. SparkNotes.com. SparkNotes LLC. 2007. Web. Diakses 30 Nov. 2013. 